\title{
The Influence of Impressed Current on Residual Bond Strength of Corroded Structure
}

\author{
SALLEHUDDIN SHAH AYOP ${ }^{1, a}$, JOHN J. CAIRNS ${ }^{2, b}$ \\ ${ }^{1}$ Universiti Tun Hussein Onn Malaysia, 86400 Pait Raja, Batu Pahat, Johor, Malaysia \\ ${ }^{2}$ Heriot Watt University, EH14 4AS Edinburgh, UK \\ asallehs@uthm.edu.my
}

Keywords: Impressed current, residual bond strength, corroded structure

\begin{abstract}
An experimental work was carried out to study the influence of impressed current on residual bond strength of corroded specimens. In accelerated corrosion process, two different current densities $0.08 \mathrm{~mA} / \mathrm{cm}^{2}$ and $0.4 \mathrm{~mA} / \mathrm{cm}^{2}$ were used which identified as 'slow' and 'fast' current. Beam end type bond specimens reinforced with $10 \mathrm{~mm}$ and $16 \mathrm{~mm}$ bar diameter were prepared for the bond test. Stirrups were provided along the main bar. Corrosion level of the main reinforcement was limited to $8 \%$ theoretical section loss. Other parameter such as the location of the test bar (corner and centre location) was also considered. The results indicate a significant influence of impressed current on the crack width with the 'fast' current tended to have wider crack than the 'slow' current. The influence on bond strength and other related parameters are being discussed.
\end{abstract}

\section{INTRODUCTION}

To study the effects of corrosion within a realistic time scale, it is sometimes necessary to accelerate degradation and to control the rate of corrosion during the propagation period [1]. The methods will vary upon the nature of corrosion under investigation. For chloride-induced corrosion, accelerated corrosion techniques are widely used to a) reduce the time taken for corrosion to initiate compared with diffusion process and $b$ ) to accelerate the rate of active corrosion. Three methods are commonly used: admixed chloride (typically $3 \%$ by weight of cement) in concrete mix, impressed voltage/current to the specimen, and wet and drying techniques which usually requires several months because they depend on the duration of the wetting and drying period.

When an impressed current is used to drive corrosion, the amount of mass loss is related to the electrical charge consumed once passivity has been compromised and can be modelled using Faraday's Law:

$$
\text { Mass loss }=\frac{M I_{\text {corr }} t}{z F}
$$

where:

$\begin{array}{lll}M & - & \text { Atomic weight of metal (56 for } \mathrm{Fe}) \\ I_{\text {corr }} & - & \text { Current (amperes) } \\ t & - & \text { Time (seconds) } \\ z & - & \text { Ionic charge }(2 \text { for } \mathrm{Fe}) \\ F & - & \text { Faraday's constant }(96,500 \text { coulombs })\end{array}$

The mass of iron $M$ consumed over time is related to the amount of current $I_{\text {corr }}$. Faraday's law is the basis for all published models that assume a constant rate of steel mass consumption and rust production i.e., for constant current, Faraday's law implies a linear increase of the loss of steel with time and also a linear increase in mass loss. The value of $z$ (valency of the reaction) is taken equal to 2 [2]. 
Some researchers have used the corrosion rate value observed on site as a reference current value for corrosion conditioning [3] [4] [1]. Based on the experimental work by Andrade and Alonso [5], the maximum corrosion rate measured in laboratory conditions without application of an impressed current is around $100 \mu \mathrm{A} / \mathrm{cm}^{2}$ (in cracked concrete submerged in seawater), while for on-site conditions, the maximum recorded $i_{\text {corr }}$ value is around $1-10 \mu \mathrm{A} / \mathrm{cm}^{2}$. Others researchers have used a different current density to accelerate the corrosion. The summary of the impressed current used by previous researchers was presented in [6].

However, it has been found that the density of impressed current has given significant effects to the level of deterioration in concrete. Andrade et al. [3] showed that for the same crack width, high corrosion rates required higher attack penetration than low corrosion rates $\left(<5 \mu \mathrm{A} / \mathrm{cm}^{2}\right)$. Therefore, for the same attack penetration, a low current produces higher crack width than a high current. In El Maaddawy and Soudki [7] work with higher impressed current, they found that the crack width increases with an increasing level of impressed current density, and noted that inducing corrosion using low current density gives corrosion products the opportunity to diffuse through the concrete pores, thus decreasing the crack width, while using high current density corrosion products will concentrate around the steel reinforcing bars, inducing higher deformation.

On bond strength, the results from Saifullah and Clark [8] show that the specimens corroded at faster rates showed considerable decreases in bond strength at the cracking stage with about $18 \%$ and $40 \%$ reduction in bond strength at current densities of 2.0 and $4.0 \mathrm{~mA} / \mathrm{cm}^{2}$ respectively. At low current density (slow rate of corrosion, less than $0.25 \mathrm{~mA} / \mathrm{cm}^{2}$ ), the amount of corrosion to cause cracking, concrete bond strength and stiffness as proportions of their non-corroded values increased with the increase in current density. However, once the current density exceeded about $0.15-0.25$ $\mathrm{mA} / \mathrm{cm}^{2}$, the value of these parameters decreased with a further increase in current density.

\section{TEST PROCEDURE}

The beam end type bond test specimens were cast into two different batches. The cross section size was $200 \mathrm{~mm}$ x $300 \mathrm{~mm}$ and the length of the specimen was $280 \mathrm{~mm}$ for the $10 \mathrm{~mm}$ reinforcing bar and $400 \mathrm{~mm}$ for the $16 \mathrm{~mm}$ reinforcing bar. The embedded lengths of main bars were decided as $185 \mathrm{~mm}$ for a $10 \mathrm{~mm}$ and $305 \mathrm{~mm}$ for a $16 \mathrm{~mm}$ bar giving a bond length/ bar diameter ratios of 18.5 and 19 respectively to ensure bond failure prior to yield of reinforcement. The specimens were divided into two groups regarding the location of the bar which is located at either the corner or in the centre of a face as in fig. 1 .

The embedded surface of the main bars was corroded by application of an impressed current with intensities of $0.4 \mathrm{~mA} / \mathrm{cm}^{2}$ or $0.08 \mathrm{~mA} / \mathrm{cm}^{2}$, defined as "fast" and "slow" current, combined with salt water spray, on a cycle of 24 hours wetting followed by 6 days dry. Flow of impressed current was measured on each specimen and Faraday's Law was used to estimate mass loss during conditioning. Conditioning was terminated when $8 \%$ mass loss was reached corresponding to corrosion penetrations of $0.20 \mathrm{~mm}$ and $0.32 \mathrm{~mm}$ for $10 \mathrm{~mm}$ and $16 \mathrm{~mm}$ bars respectively. The specimens were disconnected from the current sources for a few days while surface crack widths were measured, before load testing. Crack width readings were taken at $20 \mathrm{~mm}$ intervals along the bond length and the average calculated [9].

On the bond test, each bar was subjected to axial tension force until failure and the maximum was considered as the failure load. During the test, the free end slip was measured by a single linear variable differential transducer (LVDT) at the end of the specimen while two LVDTs were placed at the front of the specimen to measure the loaded end slip (fig. 2). 

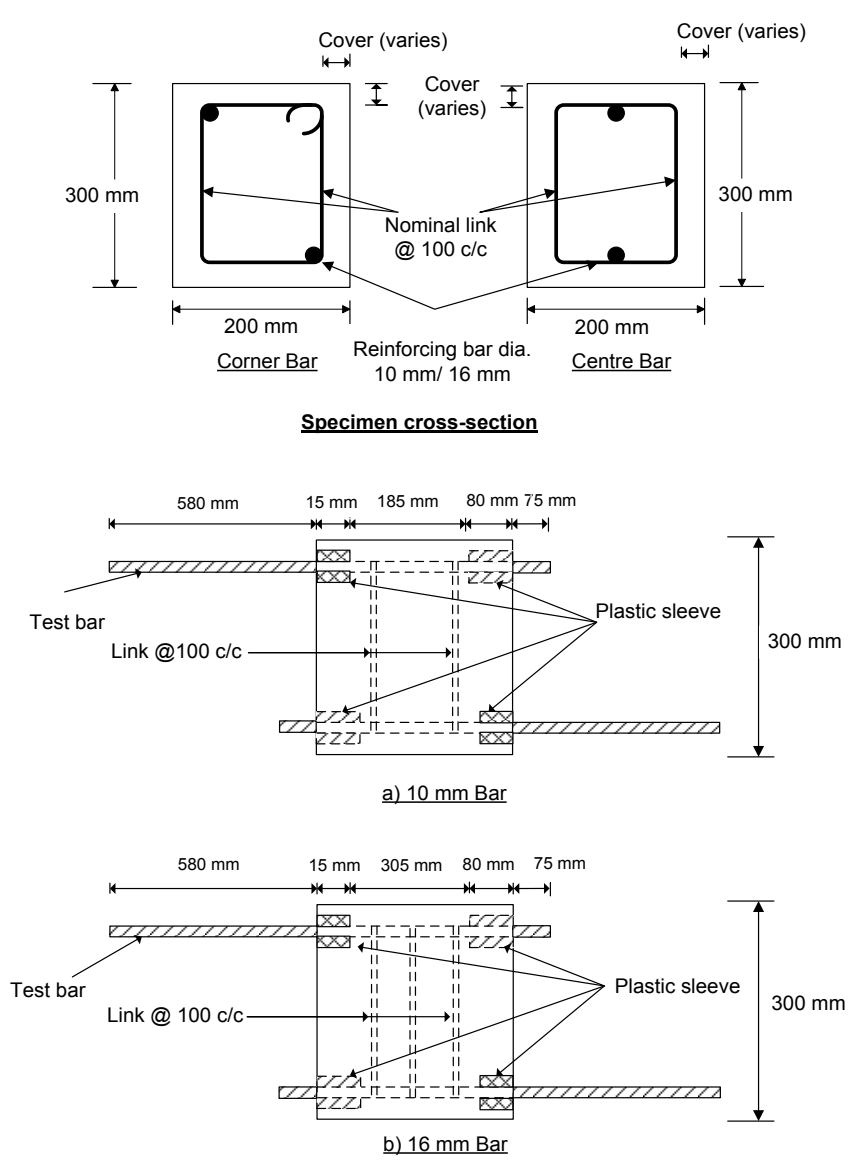

Figure 1: Detail of beam end type specimen

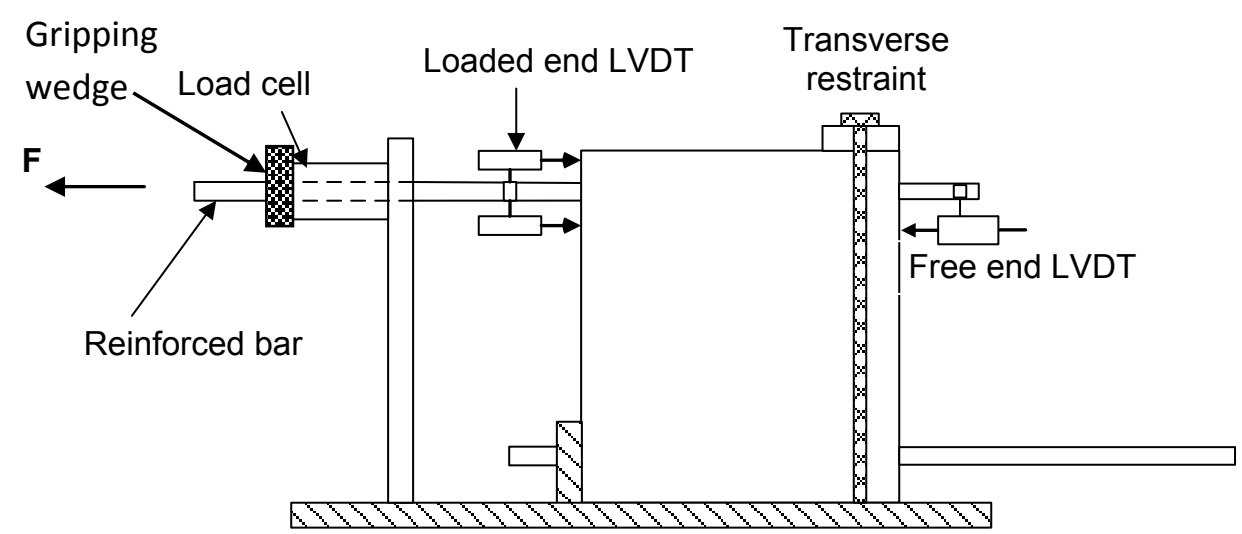

Figure 2: Bond test setup

\section{DISCUSSIONS OF EXPERIMENTAL RESULTS}

\section{Effects of impressed current on corrosion process}

The summary of average impressed current density for each batch is presented in Table 1 . As can be seen, the average current for 'fast' specimens is in the range of $0.3-0.4 \mathrm{~mA} / \mathrm{cm}^{2}$, while on the 'slow' current, the value is averaged approximately $0.08 \mathrm{~mA} / \mathrm{cm}^{2}$. The ratio of average current between first and second batch for both bar diameters and impressed currents is less than 1.25. This shows that the amount of impressed current almost similar for both 'fast' and 'slow' conditioning on different batches. 
Table 1: Impressed current analysis

\begin{tabular}{|c|c|c|c|c|}
\hline $\begin{array}{c}\text { Casting } \\
\text { batch }\end{array}$ & $\begin{array}{c}\phi \\
(\mathbf{m m})\end{array}$ & $\begin{array}{c}\text { Impressed } \\
\text { current }\end{array}$ & $\begin{array}{c}\text { Average } \\
\text { current } \\
\left(\mathrm{mA} / \mathrm{cm}^{2}\right)\end{array}$ & $\begin{array}{l}\text { Standard } \\
\text { deviation }\end{array}$ \\
\hline \multirow{4}{*}{1} & 10 & 'fast' & 0.375 & 0.075 \\
\hline & 16 & 'fast' & 0.324 & 0.102 \\
\hline & 10 & 'slow' & 0.085 & 0.003 \\
\hline & 16 & 'slow' & 0.076 & 0.005 \\
\hline \multirow{4}{*}{2} & 10 & 'fast' & 0.300 & 0.092 \\
\hline & 16 & 'fast' & 0.302 & 0.125 \\
\hline & 10 & 'slow' & 0.081 & 0.015 \\
\hline & 16 & 'slow' & 0.070 & 0.015 \\
\hline
\end{tabular}

The average gravimetric section loss for different bar positions and bar diameters are presented in fig. 3 and 4 and both figures show a following trend: (i) the actual section loss for all bar diameters is more than $4 \%$; (ii) most of the bars in the top cast position had higher levels of corrosion than those in the bottom cast position; (iii) for $16 \mathrm{~mm}$ bars, 'slow' current led to higher levels of corrosion than the 'fast' one, but the similar trend is not observed for $10 \mathrm{~mm}$ bars; and (iv) most of $10 \mathrm{~mm}$ bar had higher corrosion level than $16 \mathrm{~mm}$ bar on fast current but opposite trend shows in slow current.

A significant difference on section loss between $10 \mathrm{~mm}$ and $16 \mathrm{~mm}$ bar diameters is observed on both impressed current densities which contradicted with the almost similar amount of impressed current applied throughout the test for both bar diameters. Besides that, most of tested bars had a lower section loss less than $8 \%$. Therefore, it can be concluded that $100 \%$ current efficiency was not achieved in this experimental works. As can be expected, it might result from the leakage of impressed current which flow through alternative path during corrosion conditioning or the specimens was exposed with stray current which will lower the actual mass loss [10]. Therefore, the actual gravimetric mass loss is suitable measurement to represent the actual corrosion condition on corroded structure.

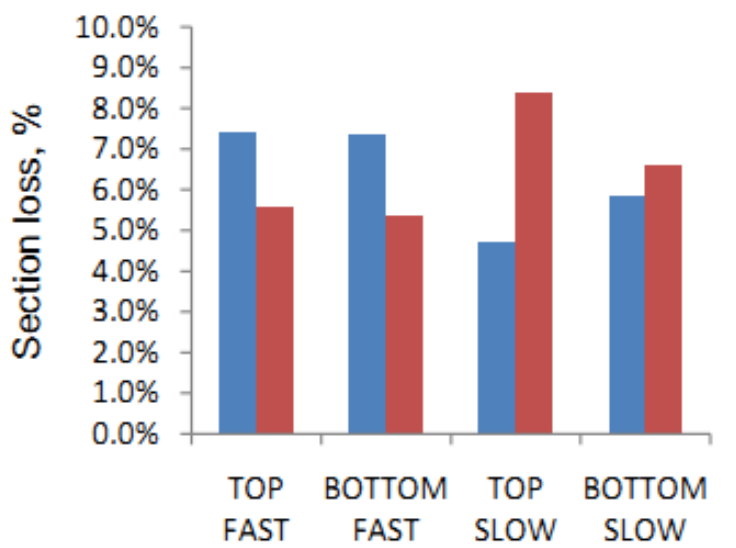

Figure 3: Average corrosion for first batch

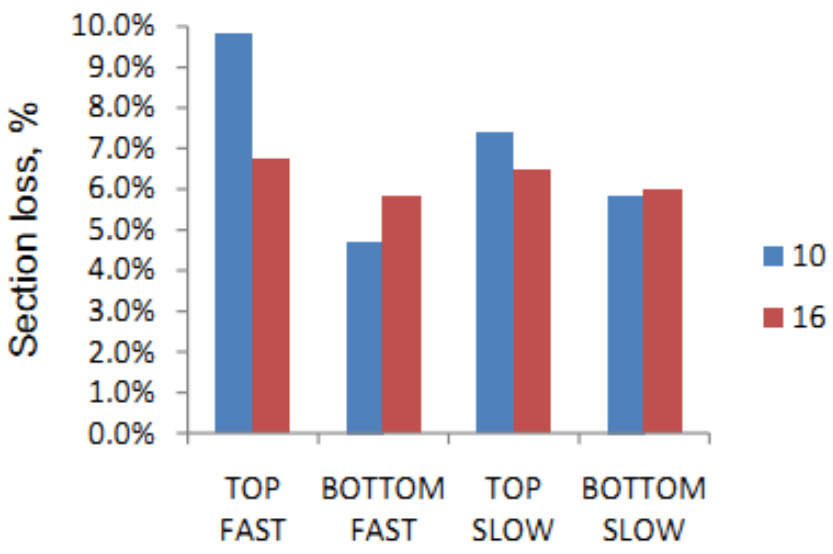

Figure 4: Average corrosion for second batch 


\section{Influence of impressed current on residual bond strength}

The influence of impressed current on surface crack width is shown in fig. 5. Wider cracks (for a given amount of corrosion) were observed for 'fast' current compared to those for the 'slow' current with the ratio of 1.2 for both bar positions. For centre bar location, lower section loss on the 'fast' current induced wider cracks compared with 'slow' current. Therefore, it might suggest that wider crack width on the 'fast' specimen is not dependent on the amount of corrosion but on the intensity of the impressed current which control the rate of corrosion. This condition is similar to the suggestion from the previous researchers about the selection of impressed current intensity and its influence on surface crack width. Furthermore, comparison is made with residual bond strength, $\mathrm{f}_{\mathrm{b}, \mathrm{r}}$. $\mathrm{f}_{\mathrm{b}, \mathrm{r}}$ is calculated by dividing the corroded bond strength with its corresponding control specimen. As can be seen, 'fast' specimens had lower residual bond strength compared with 'slow' current specimen even having almost similar corrosion penetration on the corner bar location. This trend might suggest that the amount of impressed current induced significant effects on residual bond strength and on other related corrosion parameters.

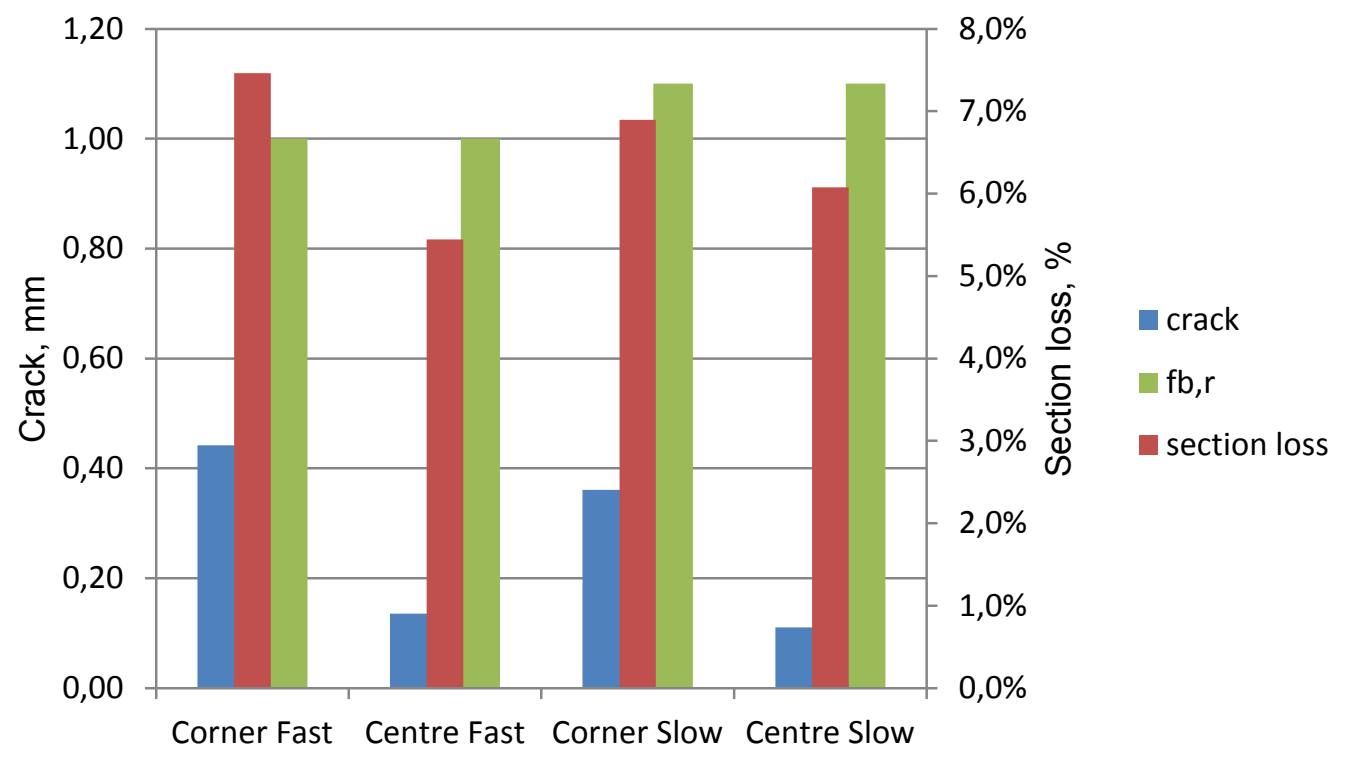

Figure 5: Average crack width for different impressed currents

\section{Conclusion}

Based on the discussions on the experimental investigation, the following conclusions can be drawn:

- Gravimetric mass loss provides an accurate measurement of corrosion condition since 100\% current efficiency was quite difficult to achieve. Therefore, the interpretation of corrosion section loss based on the total impressed current applied should be done with precaution to avoid misinterpretation of the test data.

- The selection of impressed current to accelerate the corrosion should be made with full consideration if the surface crack width as a main parameter since higher current rate had induced wider crack than slow rate of current.

- This study has highlighted the influence of impressed current on the residual bond strength. As field corrosion rates are much lower than those typically imposed in laboratory investigations, results from laboratory investigations are likely to underestimate the impact of corrosion on residual bond strengths of structures in the field. 


\section{References}

[1]

[5] C. Andrade, and C. Alonso, Corrosion rate monitoring in the laboratory and on-site,

S. A. Austin, R. Lyons and M. J. Ing, Electrochemical behaviour of steel-reinforced concrete during accelerated corrosion testing, Corrosion, 60, 2 (2004) 203- 212.

S.J. Pantazopoulou, and K.D. Papoulia, Modeling cover-cracking due to reinforcement corrosion in RC structures, Journal of Engineering Mechanics, 127, 4 (2001) 342- 351.

C. Andrade, C. Alonso, and F. J. Molina, Cover cracking as a function of bar corrosion: Part 1 - Experimental test, Materials and Structure, 26 (1993) 453-464.

J. Rodriguez, L. M. Ortega and J. Casal, Load carrying capacity of concrete structures with corroded reinforcement, Construction and Building Materials, 11, 4 (1997) pp $239-248$.

Construction and Building Materials, 10, 5 (1996) 315- 328.

S.S. Ayop and J. J Cairns, Critical Study of Corrosion Damaged Concrete Structures, International Journal of Integrated Engineering, 5, 2 (2013) p. 43-50.

T. A. El Maaddawy and K. A. Soudki, Effectiveness of impressed current technique to stimulate corrosion of steel reinforcement in concrete, Journal of Materials in Civil Engineering, 15, 1 (2003) 41-47.

M Saifullah, and L. A. Clark, Effect of corrosion rate on the bond strength of corroded reinforcement. Corrosion and Corrosion Protection of Steel in Concrete, Sheffield Academic Press, UK (1994).

T. Vidal, A. Castel, and R. Francois, Analyzing crack width to predict corrosion in reinforced concrete, Cement and Concrete Research, 34 (2004) 165-174.

L. Hariche, Y. Ballim, M. Bouhicha, S. Kenai. Effects of reinforcement configuration and sustained load on the behavior of reinforced concrete beams affected by reinforcing steel corrosion, Cement \& Concrete Composites 34 (2012) $1202-1209$. 